\title{
Quantifying Nasality in Arabic Speakers: Preliminary Data
}

\author{
https://doi.org/10.33806/ijaes2000.20.2.5
}

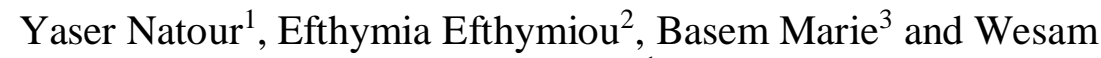 \\ Darawsheh $^{1}$ \\ The University of Jordan, Jordan ${ }^{1}$, United Arab Emirates University, \\ $U A E^{2}$, Al Ahliyya Amman University, Jordan ${ }^{3}$
}

\begin{abstract}
This paper aimed to establish preliminary normative data scores of nasalance value for the Arab Emirati speakers, and to compare them to other Arabic speakers, particularly the Saudi, Jordanian and Egyptian speakers. Design was a crosssectional study where nasality scores (nasalance percentages) were obtained under oral and vowel passage tasks. Participants were 104 Emirati individuals (54 males, age range 18-27, and 50 females, age range 18-27). Each participant was asked to extend the /a:/ vowel and read a passage in Arabic. A nasometer model II, 6450 (KayPentax, Canada) was utilized for nasalance scores computation. The ANOVA revealed no significant differences between the female and male Emirati speakers' nasalance scores in both the vowel $($ males $=26.35$, females $=23.3)$ and the oral passage tasks (males $=15$, females $=$ 15.1). The Emirati speakers had higher nasalance scores than the Saudi speakers in both tasks, and in the /a:/vowel task compared to the Egyptian and Jordanian speakers. Language and dialect are two important variables in determining the nasalance normative scores.
\end{abstract}

Keywords: Hypernasality, nasal resonance, nasality scores, normative data

\section{Introduction}

Resonance is a quality characteristic of the speech obtained by the vibration of the vocal folds resonated within the cavities of oro-naso-pharyngeal areas. Resonance, thus, depends on the construction and operation of the anatomical structures that comprise the oral, nasal and pharyngeal cavities (Kummer and Lee 1996). Hypernasality (excessive nasal resonance on non-nasal speech sounds) occurs when the soft palate does not close the nasal cavity during the production of oral sounds (Moller and Glazee 1993). Nasal vowels may be produced with some degree of nasalance (nasal resonance) which differs depending on the phonetic characteristics of each language (Benguerel, Hirose, Sawashima and Ushijima1977; Lewis, Watterson and Quint 2000).

The impaired functioning of the velopharyngeal closure causes various problems related to nasal resonance, such as, hypernasality; hyponasality (decreased nasal resonance); or assimilative nasality (nasal resonance of oral sounds adjacent to nasal sounds) (Kummer 2008b). Moreover, an impaired nasalance quality could be indicative of the presence of other speech disorders such as problems in articulation, rhythm and improper variation of voice loudness 
(Stevens, Nickerson, Boothroyd and Rollins 1976; Baken and Orlikoff 2000). The following two figures depict the normal velopharyngeal function and the incompetent velopharyngeal closure during the production of oral sounds.

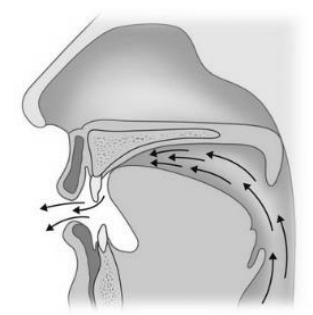

Figure 1. Normal velopharyngeal closure during the production of oral sounds

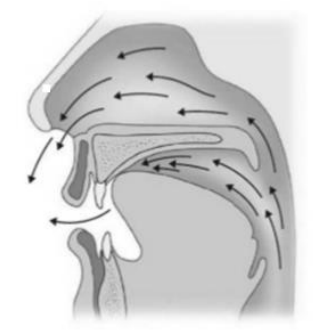

Figure 2. Incompetent velopharyngeal function during the production of oral sounds

Clinicians mainly depend on perceptual assessment of the nasalance quality as an initial method of evaluation of hypernasality (Kummer and Lee 1996). Research has shown that this method of evaluation is subjective and inaccurate in cases of hypernasality (Stevens et al. 1976). The employment of instrumental techniques to evaluate hypernasality, such as nasometry, yields quantitative measurements of nasalance quality that can be utilized clinically.

The quantitative values obtained from nasometry are compared against a set of normative values of acoustic nasalance to determine if hypernasality exists (Baken and Orlikoff 2000). However, the normative data established so far have mainly been set using the values of English speakers, which renders these data exclusive for the English language. Several factors may affect the acoustic nasalance scores such as gender, and the phonetic characteristics of each language, pertinent vowels, and derived dialects (Gildersleeve-Neumann and Dalston 2001; Pan 2004; Altakhaineh, Al-Tkhayneh and Rahrouh 2019). Arabic is an inflectional language that has velar fricatives $/ \Xi$, ${ }^{\circ} /$ and stops $/ \mathrm{k}, \mathrm{q} /$, pharyngeal fricatives / h, ?c /, and a glottal fricative /h/ and stop / $/$. As such, 
different phonemic contexts in comparison to other languages may have an effect on nasalance values.

Gender effect on nasalance scores is controversial in literature (Seaver, Dalston, Leeper and Adams 1991; Leeper, Rochet and MacKay 1992; Van Lierde, Wuyts, De Bodt and van Cauwenberge 2003; Van Lierde, Van Borsel, Cardinael, Reeckmans and Bonte 2011; Abou-Elsaad, Quriba, Baz and Elkassaby 2013; ElKassabi, Hassan, Mesallam, Malki, Farahat and Alfaris 2015). A number of laryngeal and velopharyngeal anatomical, and physiological gender-related differences, such as the size of the larynx and vocal tract, have been found to affect the nasalance scores in some studies (Van Lierde, Van Borsel, Moermanm and van Cauwenberge 2002; Van Lierde et al. 2011). Although differences between the construction and operation of palatopharyngeal region have not been fully investigated, the study of McKerns and Bzoch (1970) indicates that there are differences in the function of palatopharyngeal valve between the two genders.

Gender-related differences in the acoustic nasalance values of normal speakers who do not have hypernasality were found in some studies (Seaver et al. 1991; Leeper et al. 1992; Van Lierde et al. 2003). Mishima, Sugii, Yamada, Imura and Sugahara, (2008) reported that the nasalance scores of Japanese female speakers were significantly higher than those of Japanese male speakers; Van Lierde et al. (2003) reported that Flemish female speakers produced significantly higher nasalance scores than Flemish male speakers on oro-nasal and nasal texts, and that nasalance scores of female speakers were significantly higher in nasal consonants than male speakers. This also resonated with the results of several other studies where female speakers had a higher acoustic nasalance scores than male speakers in reading stimuli (Vallino-Napoli and Montgomery 1977; Seaver et al. 1991; Van Lierde et al. 2003). However, a study conducted by Fletcher (1976) showed otherwise where men were found to have a higher mean of acoustic nasalance than women in nasal sentences.

Other studies reported no significant gender differences in acoustic nasalance scores (Litzaw and Dalston, 1992; Kavanagh, Fee, Kalinoswki, Doyle and Leeper 1994). Lee and Browne (2012) compared adult males and females speaking Irish English and found no significant difference regarding nasalance values. Similarly, Tachimura, Mori, Hirata and Wada (2002) reported that there was not a significant gender difference in the nasalance scores between female and male Japanese speakers when reading a Japanese passage consisting of four sentences and twenty-seven non-nasal syllables.

Establishing normative data of acoustic nasalance was the purpose of several studies (Vallino-Napoli and Montgomery 1977; Seaver et al. 1991; Litzaw and Dalston 1992; Kavanagh et al. 1994; Van Lierde et al. 2003; Okalidou, Karathanasi and Grigoraki 2011; Abou-Elsaad et al. 2013; El-Kassabi et al. 2015). These studies used nasometry and took into account the specific phonetic idiosyncrasies of each language. Examples of such studies include Greek, Spanish, and Flemish (Nichols 1999; Van Lierde et al. 2003; Okalidou et al. 2011). Finnish is another example where the acoustic nasalance scores of young males and females were measured (Table 1) (Haapanen 1991). The nasalance 
scores of Spanish adult male and female speakers were generated from two dialectal regions in Mexico (Nichols 1999) and from adult female speakers in Puerto Rico (Anderson 1996). The Spanish dialect of Puerto Rico incorporated Porto Rican Hispanic female speakers aged 23-41 years (Anderson 1996). Puerto Rican female speakers exhibited slightly higher values. The acoustic nasalance scores of Cantonese Chinese dialect was also measured in Cantonese women aged 18-33 years (Whitehill 2001). Other languages were targeted such as Dutch (Whitehill 2001), Danish (Van de Weijer and Slis 1991), Canadian-French, and English dialects (Van Lierde et al. 2003; Lee and Browne 2012), Japanese (Mishima et al. 2008), and German (Kuttner, Sch"onweiler, Seeberger, Dempf, Lisson and Ptok 2003). Moreover, studies on nasalance norms have been conducted with Dutch (Hogen Esch and Dejonckere 2004), Swedish (Brunnegard, Lohmander and Van Doorn 2009), French (Leeper et al. 1992), and Australian speaking children (Van Doorn and Purcel 1998).

Comparison between acoustic nasalance values among different languages showed contradicting results. Nasalance scores of Thai and Cantonese speakers were similar to those of English speakers (Whitehill 2001; Prathanee, Thanaviratananich, Pongjunyakul and Rengpatanakij 2003). However, in another comparison, English and Spanish had more acoustic nasalance than Flemish (Van Lierde et al. 2003), and authors suggested that the differences were attributed to differing phonetic characteristics of vowels and different nasal and oral consonants existing in both English and Spanish (Leeper et al. 1992; Anderson 1996).

The effect of different dialects on nasalance has many contentions (Seaver et al. 1991; Leeper et al. 1992; Van Lierde et al. 2003). Baken and Orlikoff (2000) state that clinicians need to gather their own set of data because nasalance scores are known to be sensitive to dialect variations. Thus, a number of studies were initiated to investigate the effect of dialectical differences on nasality scores. Seaver et al. (1991) found significantly higher nasalance scores in Mid-Atlantic speakers of various dialects of English compared to normal adults from another three geographical areas of North America (Sothern, Mid-Western, Ontario Canada). The Mid-Atlantic speakers were reported to have significantly higher nasalance scores in Zoo and Rainbow passages and nasal sentences than speakers from the other three regions selected in North America. Additionally, normal typical female speakers, showed significantly higher nasalance scores in sentences with nasal consonants in all regions. Conversely, Kavanagh et al. (1994) found no significant differences in nasalance scores between male and female speakers, producing the same three sentences, and among the three dialect groups of Halifax, Moncton and St. John's. Consequently, studies on gender-related and dialectal differences have not produced consistent results even when the same linguistic stimuli were used. Table 1 summarizes the normative nasality scores across different languages and dialects as found in the literature.

There was a scarcity of studies done to investigate acoustic nasalance scores in Arabic speakers for clinical purposes, and even for the purpose of establishing normative scores of acoustic nasalance. El-Mansi and El-Halees (1992) studied 
the norms of nasalance in Jordanian speakers in children (60 males and 50 females) and adults (60 males and 60 females). Nasalance was measured for three passages; one included Arabic phonemes with no nasals, the second included phonetically balanced phonemes, and the third included nasal phonemes.

Table 1. Nasality scores across different languages and dialects

\begin{tabular}{|c|c|c|c|c|c|}
\hline \multirow[t]{2}{*}{ Language } & \multirow[t]{2}{*}{$\mathbf{N}$} & Oral task & $\begin{array}{l}\text { Oral-Nasal } \\
\text { Task }\end{array}$ & $\begin{array}{l}\text { Nasal } \\
\text { Task }\end{array}$ & \multirow[t]{2}{*}{ Study } \\
\hline & & $\begin{array}{l}\text { Mean } \pm \text { SD or } \\
\text { (range) }\end{array}$ & $\begin{array}{c}\text { Mean } \pm \text { SD or } \\
\text { (range) }\end{array}$ & $\begin{array}{l}\text { Mean } \pm \text { SD } \\
\text { or (range) }\end{array}$ & \\
\hline \multirow{2}{*}{$\begin{array}{l}\text { Flemish } \\
\text { (Belgium) }\end{array}$} & Adult men \& & M 10.2 \pm 1.3 & M 31.5 \pm 0.8 & $\mathrm{M}$ & \multirow[t]{2}{*}{ (1) } \\
\hline & $\begin{array}{l}\text { women }(19-27 \mathrm{yrs}) \\
\mathrm{N}=58\end{array}$ & F $11.6 \pm 1.3$ & F $36.1 \pm 0.9$ & $\begin{array}{l}54.2 \pm 0.8 \\
\text { F } 57.4 \pm 0.8\end{array}$ & \\
\hline \multirow[t]{2}{*}{ Japanese } & Adult Japanese & M $10.3 \pm 5.8$ & NA & NA & \multirow[t]{2}{*}{ (2) } \\
\hline & $\begin{array}{l}\text { from four regions } \\
\text { in (Men: } 23.8 \mathrm{yrs} \text {; } \\
\text { Women: } 23.2 \mathrm{yrs} \text { ) } \\
\mathrm{N}=68\end{array}$ & F $15.6 \pm 8.4$ & NA & NA & \\
\hline Irish English & $\begin{array}{l}\text { Adult men \& } \\
\text { women }(18-28) \\
\mathrm{N}=60\end{array}$ & $11.5 \pm 2.9$ & $29.6 \pm 5$ & $47.6 \pm 6.6$ & (3) \\
\hline \multirow[t]{4}{*}{ Greek } & Adult & & & & \multirow[t]{4}{*}{ (4) } \\
\hline & Males (18-32) & $\mathrm{M}$ & M & M & \\
\hline & $\mathrm{N}=40$ & $12 \pm 4.7$ & $25.3 \pm 5$ & $42.4 \pm 6.6$ & \\
\hline & $\begin{array}{l}\text { Females }(18-34) \\
\mathrm{N}=40\end{array}$ & F $13.1 \pm 5.1$ & F $25.7 \pm 5.8$ & F $42.3 \pm 8.7$ & \\
\hline \multirow[t]{2}{*}{ Spanish } & $\begin{array}{l}\text { Adult men \& } \\
\text { women }(20-40 \mathrm{yrs}) \\
\& \text { children }(6-13 \\
\text { yrs) Mexico } \\
\mathrm{N}=152\end{array}$ & $17.0 \pm 6.7$ & NA & $55.6 \pm 6.0$ & $(5)$ \\
\hline & $\begin{array}{l}\text { Adult women (21- } \\
43 \text { yrs) Puerto } \\
\text { Rico } n=40\end{array}$ & $21.9 \pm 8.6$ & $36.0 \pm 7.0$ & $63.0 \pm 7.7$ & (6) \\
\hline Finnish & $\begin{array}{l}\text { Adults \& } \\
\text { preschool/ } \\
\text { school age } \\
\text { children }(3-54 \text { yrs) } \\
\mathrm{N}=42\end{array}$ & $13.6 \pm 5.6$ & NA & $69.4 \pm 8.2$ & (7) \\
\hline Cantonese & $\begin{array}{l}\text { Adult women from } \\
\text { China (18-33 yrs) } \\
\mathrm{N}=141\end{array}$ & $13.6 \pm 7.1$ & $35.4 \pm 6.2$ & $55.6 \pm 7.3$ & $(8)$ \\
\hline Swedish & $\begin{array}{l}\text { Children (6-11 yrs) } \\
\mathrm{N}=245\end{array}$ & $12.7 \pm 5.6$ & $29.5 \pm 6.1$ & $56.5 \pm 6.0$ & (9) \\
\hline Thai & $\begin{array}{l}\text { Children (7-12 yrs) } \\
\mathrm{N}=141\end{array}$ & $14.3 \pm 5.8$ & $35.6 \pm 5.9$ & $51.1 \pm 6.4$ & $(10)$ \\
\hline Portuguese & Adult men \& & $10.0 \pm 3.15$ & $44.0 \pm 8.07$ & $\mathrm{NA}$ & $(11)$ \\
\hline
\end{tabular}




\begin{tabular}{|c|c|c|c|c|c|}
\hline & $\begin{array}{l}\text { women (19-27 yrs) } \\
\mathrm{N}=25\end{array}$ & & & & \\
\hline \multirow[t]{2}{*}{ Hungarian } & $\begin{array}{l}\text { Adults }(20-25 \text { yrs }) \\
\mathrm{N}=45\end{array}$ & $\begin{array}{l}13.4(10.2- \\
16.5)\end{array}$ & $\begin{array}{l}39.5(31.4- \\
47.6)\end{array}$ & $\begin{array}{l}56.0(52.6- \\
63)\end{array}$ & (12) \\
\hline & $\begin{array}{l}\text { Children }(5-7 \text { yrs }) \\
\mathrm{N}=30\end{array}$ & $\begin{array}{l}11.0(9.5- \\
16.5)\end{array}$ & $\begin{array}{l}31.7(23.8- \\
39.7)\end{array}$ & $\begin{array}{l}50.6(46.3- \\
57.4)\end{array}$ & \\
\hline Canadian & Children \& & M 9.2 44.1 & $24.0 \pm 4.4$ & $33.4 \pm 6.1$ & (13) \\
\hline French & $\begin{array}{l}\text { Adolescents (9-19 } \\
\text { yrs) } \mathrm{N}=59\end{array}$ & F $8.8 \pm 2.3$ & $25.3 \pm 3.5$ & $35.6 \pm 5.1$ & \\
\hline
\end{tabular}

Note. $\mathrm{N}=$ Number, $\mathrm{M}=$ Male, $\mathrm{F}=$ Female, $\mathrm{NA}=$ unavailable from the source, (1) Van Lierde et al. (2011); (2) Mishima et al. (2008); (3) Lee and Browne (2012); (4) Okalidou et al. (2011); (5) Nicholas (1999); (6) Haapanen (1991); (7) Whitehill (2001); (8) Brunnegard and Van Doorn (2009); (9) Prathanee et al. (2003); (10) Falé and Faria (2008); (11) Hirschberg, Bók, Juhász, Trenovski, Votisky and Hirschberg (2006); (12) Rochet, Rochet, Sovis and Mielke (1998); (13) Anderson (1996).

In addition, El-Mansi and El-Halees (1992) measured nasalance in three sustained vowels /i:/, /a:/, and /u:/. They reported that females had higher nasalance in comparison to males. However, looking closely at the reported results, the difference between nasalance in males and females was more evident in sustained vowels $(\mathrm{F}=23.8, \mathrm{M}=20.1)$ rather than passages $(\mathrm{F}=16.3, \mathrm{M}=16.1)$.

Abou-Elsaad et al. (2013) collected normative nasalance scores in 300 healthy Egyptian speakers of various ages and groups. Three groups were involved (92 children 3-9 years; 76 teenagers 9-18 years; 132 adults 18+years). Tasks were derived from the Arabic Simplified Nasometric Assessment Procedures (SNAP). This assessment procedure was modified from its original version (MacKay-Kummer SNAP test- RC) (Kummer, 2008a) to Arabic and validated by Abou-Elsaad et al. (2013) and included the following tasks: oral \& /a:/ syllable, oral \& /i:/ syllable, nasal \& /a:/ syllable, nasal \& /i:/ syllable, sustained sounds, picture-cued subtest, reading passage subtest. There were significant gender differences in the reading passage nasalance scores but not the /a:/ task scores. Such data is clinically meaningful and usable in patients with abnormal nasalance, such as velopharyngeal incompetency and/or insufficiency. For example, Abou-Elsaad, Afsah, Baz and Mansy (2016) have conducted a study to evaluate the accuracy of Arabic Simplified Nasometric Assessment Procedures (SNAP) test with children with hypernasality. The authors set forth to compare the scores of 92 children without nasalance abnormalities with the scores of 30 children with velopharyngeal insufficiency. It was found that the Arabic SNAP test was a reliable tool for the assessment of children with hypernasality.

Normative nasalance scores for Saudi population were investigated by ElKassabi et al. (2015). The authors compared scores of four different groups (adult females, age range of 17- 55 years, adult males, age range of 18-54 years, female children, age range of 4-14 years, and male children, age range of 4-12 years) and 
found significant differences between the four groups; nasalance was higher in adult and female groups.

This study aimed at developing clinical normative data of acoustic nasalance for Emirati Arabic speaking population. It compared the acoustic nasalance scores of both genders and compared results with those of the Jordanian, Egyptian and Saudi populations.

\section{Method}

\subsection{Participants}

The total number of participants was 104 healthy Emiratis (54 males, age range 18 -27, mean age $21.7 \pm 2$; and 50 females, age range 17-24, mean age $21.3 \pm 1.7$ ) speaking the Emirati dialect of Arabic. Participants were conveniently recruited from the University of United Arab Emirates, following the ethical standards of anonymity, confidentiality and attaining participants' consent. Participants were recruited on volunteer basis following the principles outlined in the Declaration of Helsinki. No power analysis was performed to determine the sample size, because the sample was a convenient one. At the time of recording, the participants did not have any cold or flu symptoms, or a prior history of voice and/or nasality related systemic diseases. Furthermore, perceptual assessment was performed by three experienced speech-language pathologists to exclude the presence of any nasality issues at the time of the study. Nasalance scores (in percentages) were collected by two experienced speech-language pathologists.

\subsection{Data collection and analysis}

All subjects were instructed to phonate the /a:/ vowel (Kalaldeh, 2018) (nasometer time window was predefined as 200 milliseconds), and to read an oral passage with non-nasal sounds (free of the only two nasal sounds in Arabic the $/ \mathrm{n} /$ and $/ \mathrm{m} /$ ) (Appendix 1). In the current study, nasal and oro-nasal stimuli were not used to generate the feature of acoustic nasalance. It was assumed that nasalance was a condition clinically evident in oral sounds, more than nasal or oro-nasal sounds. The aim was to establish preliminary normative scores of nasalance in non-nasal sounds, i.e. purely oral, thus the comparison of normative acoustic nasalance scores would be more evident for the detection of abnormal hypernasality.

The reading passage was developed by the authors in Modern Standard Arabic (MSA) so that it can be of clinical use for estimating hypernasality in the general Arab population. It consisted of 126 words that formed meaningful, easy to read set of sentences and phrases. The 26 non-nasal Arabic consonants (Amayreh 2003) were included in the reading passage (excluding the two nasal stops $/ \mathrm{m}, \mathrm{n} /$ ). The reading passage is phonetically transcribed in Appendix 1 using the International Phonetic Alphabet (IPA). Each subject was asked to produce two trials (i.e. two consecutive trials for each of the vowel and the reading passage) for the purposes of reliability testing. Samples were input into the Nasometer model II 6450 (KayPentax Medical, Canada) via the designated headset with two acoustic channels: oral and nasal. Recording was conducted in a quiet room to ensure recording quality. The nasometer was calibrated before each 
data collection session. The subjects reported that they had no infections, respiratory stress or voice/resonance problems at the time of recording.

The percentage of nasalance scores were calculated for both the vowel and the reading paragraph. This was conducted by measuring the amplitude of the acoustic energy generated only from the nasal cavity divided by the amplitude of the acoustic energy from both the oral and the nasal cavities (Baken and Orlikoff 2000). The reliability of the participants' responses was evaluated by Spearman's rho test correlating their two trials of the vowel and the reading paragraph. A test of Analysis of Variance (2-Way ANOVA) was conducted to compare the nasalance scores under the two tasks (vowel and reading passage) of the male and female participants in order to find out if there were significant differences between the two groups. The statistical analysis was executed using IBM SPSS software, Version 22.0 (SPSS, Chicago, USA).

Finally, a comparison among Emirati, Jordanian, Saudi and Egyptian speakers of Arabic was conducted.

\section{Results}

The mean nasalance scores for males was $26.35(\mathrm{SD}=17.95)$ for the /a:/ vowel and $15(\mathrm{SD}=5.7)$ for the reading passage; while the mean nasalance scores for females was $23.3(\mathrm{SD}=17)$ for the /a:/ vowel and 15.1 $(\mathrm{SD}=5.9)$ for the reading passage. Results of the ANOVA revealed no significant differences between female and male scores in both the vowel task $\left(1^{\text {st }}\right.$ trial $P 0.481,2^{\text {nd }}$ trial $\left.P 0.169\right)$ and the passage task $\left(1^{\text {st }}\right.$ trial $P 0.730,2^{\text {nd }}$ trial $P$ 0.650). Spearman's Rho test revealed a strong positive correlation for participants' scores between the vowel task $(r .877)$ and the reading passage task $(r$.862). Table 2 shows the means and standard deviations of nasalance scores for both the vowel and the reading passage for males and females.

Table 2. Means and SDs of nasalance scores

\begin{tabular}{llllll}
\hline \multirow{2}{*}{ Tasks } & \multicolumn{2}{c}{ Male } & & \multicolumn{2}{c}{ Female } \\
\cline { 2 - 3 } \cline { 5 - 6 } & Mean & SD & & Mean & SD \\
\hline /a:/ $1^{\text {st }}$ trial & 25.40 & 16.80 & & 23.60 & 17.00 \\
\hline /a:/ $2^{\text {nd }}$ trial & 27.30 & 19.10 & & 23.00 & 17.00 \\
\hline Mean of trials $(/ \mathrm{a}: /)$ & 26.40 & 18.00 & & 23.30 & 17.00 \\
\hline Paragraph $1^{\text {st }}$ trial & 15.00 & 5.70 & & 15.60 & 6.50 \\
\hline Paragraph $2^{\text {nd }}$ trial & 15.00 & 5.70 & & 14.60 & 5.70 \\
\hline Mean of trials $($ passage $)$ & 15.00 & 5.70 & & 15.10 & 6.10 \\
\hline
\end{tabular}

Note. $\mathrm{SD}=$ Standard Deviation.

Emirati Arabs had higher nasalance scores than the Saudis in both tasks. Furthermore, Emiratis had higher nasalance scores in the vowel /a:/ than the Egyptians and relatively, the Jordanians . However, the Egyptian and Jordanian nasalance scores in the reading passage were higher than both the Emirati and the Saudi scores. Table 3 shows a comparison between the four Arab nationalities. 
Table 3. Results of nasalance scores across Emirati, Saudi and Egyptian speakers

\begin{tabular}{|c|c|c|c|c|c|}
\hline $\begin{array}{l}\text { Arabic } \\
\text { Speakers }\end{array}$ & $\mathbf{N}$ & $\begin{array}{l}\text { Age } \\
\text { range } \\
\text { (vrs) }\end{array}$ & Age (yrs) & $\begin{array}{l}\text { Oral sentence/ } \\
\text { passage }\end{array}$ & /a:/ vowel \\
\hline & & & Mean \pm SD & Mean \pm SD & Mean \pm SD \\
\hline Emirati & $\begin{array}{l}\mathrm{M} \\
(\mathrm{N}=54)\end{array}$ & $18-27$ & $21.7 \pm 2.0$ & M $15.0 \pm 5.7$ & M $26.4 \pm 18.0$ \\
\hline $\begin{array}{l}\text { Current } \\
\text { study }\end{array}$ & $\begin{array}{l}\mathrm{F} \\
(\mathrm{N}=50)\end{array}$ & $17-24$ & $21.3 \pm 1.7$ & $\begin{array}{l}\text { F } 15.1 \pm 6.1 \\
\text { Insignificant in } \\
\text { both trials }(\mathrm{p}= \\
0.730, \mathrm{p}=0.650)\end{array}$ & $\begin{array}{l}\text { F } 23.3 \pm 17 \\
\text { Insignificant in } \\
\text { both trials }(p= \\
0.481, p=0.169)\end{array}$ \\
\hline Jordanian & $\begin{array}{l}\mathrm{M} \\
(\mathrm{N}=60)\end{array}$ & $20-40$ & & M 16.1 & M 20.1 \\
\hline $\begin{array}{l}\text { El-Mansi } \\
\text { and El- } \\
\text { Halees } \\
(1992)\end{array}$ & $\begin{array}{l}\mathrm{F} \\
(\mathrm{N}=60)\end{array}$ & $20-40$ & & $\begin{array}{l}\text { F } 16.3 \\
\text { P value not } \\
\text { provided }\end{array}$ & $\begin{array}{l}\text { F } 23.8 \\
\text { P value not } \\
\text { provided }\end{array}$ \\
\hline Egyptian & $\begin{array}{l}\mathrm{M} \\
(\mathrm{N}=62)\end{array}$ & $18-54$ & $34.1 \pm 9.0$ & M $29.0 \pm 13.0$ & 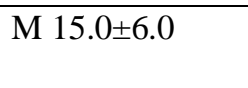 \\
\hline $\begin{array}{l}\text { Abou-Elsaad } \\
\text { et al. (2013) }\end{array}$ & $\begin{array}{l}\mathrm{F} \\
(\mathrm{N}=70)\end{array}$ & $18-54$ & $34.1 \pm 9.0$ & $\begin{array}{l}\text { F } 30.0 \pm 21.0 \\
\text { Insignificant } \\
P=0.74\end{array}$ & $\begin{array}{l}\text { F } 22.0 \pm 15.0 \\
\text { Significant } \\
P=0.001\end{array}$ \\
\hline Saudi & $\begin{array}{l}\mathrm{M} \\
(\mathrm{N}=73)\end{array}$ & $18-54$ & $34.4 \pm 9.3$ & M 9.75 43.03 & M $11.8 \pm 6.3$ \\
\hline $\begin{array}{l}\text { El-Kassabi } \\
\text { et al. (2015) }\end{array}$ & $\begin{array}{l}\mathrm{F} \\
(\mathrm{N}=71)\end{array}$ & $17-55$ & $32.1 \pm 10.1$ & $\begin{array}{l}\text { F } 11.17 \pm 5.13 \\
\text { Insignificant } \\
\text { P Value not } \\
\text { provided }\end{array}$ & $\begin{array}{l}\text { F } 10.3 \pm 5.0 \\
\text { Insignificant } \\
\text { P Value not } \\
\text { provided }\end{array}$ \\
\hline
\end{tabular}

Note. $\mathrm{SD}=$ Standard Deviation, $\mathrm{N}=$ number, $\mathrm{M}=$ Males, $\mathrm{F}=$ Females.

\section{Discussion}

\subsection{Nasalance scores: the influence of gender}

When comparing the performance of both genders on the two common tasks (the reading passage and the vowel (a:/) both the current study and the study conducted by El-Kassabi et al. (2015), showed insignificant gender differences in both tasks. This also concurs with the results of other studies (Litzaw and Dalston 1992; Kavanagh et al. 1994; Tachimura et al. 2000; Okalidou et al. 2011), where no significant differences were found between males and females.

The study conducted by Abou-Elsaad et al. (2013), on Egyptian Arabs showed only a significant gender difference in the reading passage nasalance scores but not the /a:/ task scores (Table 3). On the other hand, El-Mansi and ElHalees (1992) reported that females had significantly higher nasalance in vowels rather than reading passages for Jordanian speakers. In other studies, (Seaver et al. 1991; Leeper et al. 1992; Van Lierde et al. 2003; Mishima et al. 2008; ElKassabi et al. 2015), the general trend of the results was favoring higher nasalance scores in females than males with some variations between them. The variation of 
results related to gender could be attributed to methodological variations in, for example, sample size and age groups. This could also be due to the assumption that gender is of a minimal influence on nasalance scores especially if compared with other factors such as probable dialect influences.

\subsection{Nasalance scores: the influence of dialect}

Table 3 shows the differences in the mean nasal scores between the dialect in this study and those of the Saudi (El-Kassabi et al. 2015), the Egyptian dialects (Abou-Elsaad et al. 2013) and the Jordanian Arabic (El-Mansi and El-Halees 1992) in both tasks of /a:/ production and the reading passage. The Egyptian study (Abou-Elsaad et al. 2013) mean nasalance score in the oral sentences was higher than the mean nasalance scores of the Emirati, the Saudi, and the Jordanian dialects, respectively (El-Kassabi et al. 2015). The Egyptian study utilized a passage that is formed and presented in the Egyptian dialect whereas in the current study a passage was constructed using MSA. This is an evidence of the influence of dialect on nasalance scores as reflected by the variations in their values. The Emirati speakers had higher mean nasalance scores than the Saudi speakers (El-Kassabi et al. 2015) who speak a somewhat similar Arabic dialect, namely, the Gulf Region Arabic (Holes 2001). This could be attributed to methodological differences between the two studies as El-Kassabi et al. (2015) utilized a set of three oral sentences spoken in Saudi Arabic whereas the current study used a passage written in MSA.

\subsection{Limitations of the study and directions for future research}

In the current study, only oral stimuli were used to generate the feature of acoustic nasalance which may be dependent on language, dialect, and individual variations. Future research may include analysis of broader phonetic contexts (e.g. other Arabic vowels and nasal, oral and oro-nasal stimuli).

Further research studies need to focus on the possible influence of dialects such as dialects of the Levant (e.g. Lebanese / Jordanian Arabic) and dialects of the Western Arabic (e.g. Moroccan/ Algerian Arabic) using the same MSA reading passage constructed for this study (Appendix 1). This would allow for rigorous/systematic comparisons of nasalance scores obtained in this study as pertinent to the various dialects of Arabic.

A unique result of this study is the presence of any effect of speaker nationality on nasalance scores in the steady state vowel of /a:/, which requires further investigation. Future research studies can be conducted to investigate the effect of various MSA dialects on the nasalance in all six MSA monophthongs.

\section{Conclusion}

The current study is concurrent with the corpus of contentions available in the literature concerning the association between gender and nasalance. Though results from the literature review yields a trend of higher nasalance scores in females than males, this study did not reveal any significant difference in nasalance scores attributed to gender regardless of the task, i.e. vowel or passage. 
The variation of the literature review results related to effect of gender on nasalance scores could be attributed to methodological variations and to the presence of other factors that were of more influential effect on nasalance scores, e.g. task and dialect. Thus, gender is a variable that needs further investigation since the available evidence is not yet conclusive.

Emirati speakers had higher nasalance scores than the Saudi speakers in both, the vowel /a:/ and reading tasks. They also had higher nasalance scores in the vowel task but not the passage task than speakers of the Jordanian and Egyptian Arabic dialects. This study emphasized the potent effect of the nature of the task on nasalance scores. The finding in the current investigation that steady state vowels have nasalance quality, represented herein in the /a:/ vowel calls for further investigation. Future research studies need to be conducted on other Arab speakers while replicating the same methodological approach of this study. They can also focus on exploring the effect of dialects on nasalance in the MSA monophthongs.

${ }^{1}$ Yaser Natour $(\mathrm{PhD})$,

University of Jordan, Jordan

Email: natour@fulbrightmail.org

Wesam Darawsheh $(\mathrm{PhD})$, University of Jordan, Jordan

Email:w.darawsheh@gmail.com

${ }^{2}$ Efthymia Efthymiou (PhD), United Arab Emirates University, UAE

Email: efthymia effie.efthymiou@gmail.com

${ }^{3}$ Basem Marie $(\mathrm{PhD})$, Al Ahliyya Amman University, Jordan

Email: basem.marie@fulbrightmail.org 


\section{References}

Abou-Elsaad, Tamer, Omayma Afsah, Hemmat Baz and Alzahraa Mansy. (2016). 'Evaluating the diagnostic accuracy of Arabic SNAP test for children with hypernasality'. International Journal of Pediatric Otorhinolaryngology, 85:99-102.

Abou- Elsaad, Tamer, Amal Quriba, Hemmat Baz and Rasha Elkassaby. (2013). 'Standardization of nasometry for normal Egyptian Arabic speakers'. Folia Phoniatrica et Logopaedica, 64 (6):271-277.

Altakhaineh, Abdel Rahman, Khawlah Al-Tkhayneh and Hanan Rahrouh. (2019). 'The Effect of the Gender and Culture of the IELTS Examiner on the Examinees' Performance on the IELTS Speaking Test in the UAE Context'. International Journal of Arabic-English Studies (IJAES), 19 (1): 33-52.

Amayreh, Mousa. (2003). 'Completion of the Consonant Inventory of Arabic'. Journal of Speech Language and Hearing Research, 46:517-529.

Anderson, Raquel. (1996). 'Nasometric values for normal Spanish-speaking females: A preliminary report'. Cleft Palate-Craniofacial Journal, 33:333336.

Baken, Roland and Robert Orlikoff. (2000). Clinical Measurement of Speech and Voice ( $2^{\text {nd }}$ edition). San Diego, CA: Singular Publishing Group.

Benguerel, André-Pierre, Haj ime Hirose, Masayuki Sawashima and Tatsujiro Ushijima. (1977). 'Velar coarticulation in French: An electromyographic study'. Journal of Phonetics, 5:159-167.

Brunnegard, Karin, Anette Lohmander and Jan van Doorn. (2009). 'Untrained listeners' ratings of speech disorders in a group with cleft palate: a comparison with speech and language pathologists' ratings'. International Journal of Language \& Communication Disorders, 44 (5):656-74.

El-Kassabi, Rasha, Sabah Hassan, Tamer Mesallam, Khalid Malki, Mohamed Farahat and Abdullah Alfaris. (2015). 'Standardization of nasalance scores in normal Saudi speakers'. Logopedics Phoniatrics Vocology, 40:77-85. 
El-Mansi, Hanan, and Yousef El-Halees. (1992). A study of nasalance norms in Arabic speech. MA Thesis, The University of Jordan, Amman, Jordan.

Falé, Isabel and Isabel Faria. (2008). 'Nasometric values for European Portuguese: preliminary results'. Proceedings of the ISCA Workshop on Experimental Linguistics. Athens, Greece.

Fletcher, Samuel (1976). 'Nasalance vs. listener judgment of nasality'. Cleft Palate Journal, 13:31-44.

Gildersleeve-Neumann, Christina and Rodger Dalston. (2001). 'Nasalance scores in noncleft individuals: why not zero?'. Cleft Palate-Craniofacial Journal, 38:106-111.

Haapanen, Marja-Leena (1991). 'Nasalance scores in normal Finnish speech'. Folia Phoniatrica et Logopaedica, 43:197-203.

Hirschberg, Jenő, Szilvia Bók, Márta Juhász, Zsuzsa Trenovski, Péter Votisky and Andor Hirschberg. (2006). 'Adaptation of Nasometry to Hungarian language and experiences with its clinical application'. International Journal of Pediatric Otorhinolaryngology, 70:785-798.

Hogen Esch, Thijs and Philippe Dejonckere. (2004). 'Objectivating nasality in healthy and velopharyngeal insufficient children with the nasalance acquisition system (NasalView). Defining minimal required speech tasks assessing normative values for Dutch language'. International Journal of Pediatric Otorhinolaryngology, 68 (8):1039-1046.

Holes, Clive. (2001). Dialect, Culture, and Society in Eastern Arabia: Glossary. Leiden: The Netherlands PA: Brill.

Kalaldeh, Raya. (2018). 'Acoustic analysis of modern standard Arabic vowels by Jordanian speakers'. International Journal of Arabic-English Studies (IJAES), 18 (1): 23-28.

Kavanagh, Mary Lou, Jane Fee, Joseph Kalinoswki, Philip Doyle and Herbert Leeper. (1994). 'Nasometric values for three dialectical groups within the Atlantic Provinces of Canada'. Journal of Speech Language Pathology and Audiology, 18:7-13.

Kummer, Ann. (2008a). Cleft Palate and Craniofacial Anomalies: Effects on Speech and Resonance ( $2^{\text {nd }}$ edition). Clifton Park, NJ: Delmar Cengage Learning.

Kummer, Ann. (2008b). 'Nasometry'. In: Ann. Kummer (ed.), Cleft Palate and Craniofacial Anomalies: Effects on Speech and Resonance ( $2^{\text {nd }}$ edition). Clifton Park, NY: Thomson Delmar Learning.

Kummer, Ann and Linda Lee. (1996). 'Evaluation and treatment of resonance disorders'. Language Speech and Hearing Services in Schools, 27:271-281.

Küttner, Christian, Rainer Sch"onweiler, Bernd Seeberger, Rupert Dempf, Jörg Lisson and Martin Ptok. (2003). 'Normal nasalance for the German language. Nasometric values for clinical use in patients with cleft lip and palate'. $H N O, 51: 151-156$.

Lee, Alice and Una Browne. (2012). 'Nasalance scores for typical Irish Englishspeaking adults'. Logopedics Phoniatrics Vocology, 38:167-172. 
Leeper, Herbert, Anne Rochet and Ian MacKay (1992). 'Characteristics of nasalance in Canadian speakers of English and French'. Proceedings of the International Conference on Spoken Language Processing, 49-52. Banff, Alberta.

Lewis, Kerry, Thomas Watterson and Teresa Quint. (2000). 'The effect of vowel on nasalance scores'. The Cleft Palate-Craniofacial Journal, 37:584589.

Litzaw, Laura and Rodger Dalston. (1992). 'The effect of gender upon nasalance scores among normal adult speakers'. Journal of Communication Disorders, 25:55-64.

McKerns, David and Kenneth Bzoch. (1970). 'Variations in velopharyngeal valving: The factor of sex'. The Cleft Palate-Craniofacial Journal, 7:65262.

Mishima, Katsuaki, Asuka Sugii, Tomohiro Yamada, Hidcto Imura and Toshio Sugahara. (2008). 'Dialectal and gender differences in nasalance scores in a Japanese population'. Journal of Cranio-Maxillo-Facial Surgery, 36:8-10.

Moller, Karlind and Leslie Glaze. (1993). Cleft Lip and Palate: Interdisciplinary Issues and Treatment ( $2^{\text {nd }}$ edition). Austin TX: Pro-Ed.

Nichols, Alan. (1999). 'Nasalance statistics for two Mexican populations'. Cleft Palate-Craniofacial Journal, 36:57-63.

Okalidou, Areti, Asimina Karathanasi and Eleni Grigoraki. (2011). 'Nasalance norms in Greek adults'. Clinical Linguistics \& Phonetics, 8:67188.

Pan, Ho-Hsien. (2004). 'Nasality in Taiwanese'. Language and Speech, 47 (3):267-296.

Prathanee, Benjamas, Sanguansak Thanaviratananich, Amomrat Pongjunyakul and Kanda Rengpatanakij. (2003). 'Nasalance scores for speech in normal Thai children'. Scandinavian Journal of Plastic and Reconstructive Surgery and Hand Surgery, 37:351-355.

Rochet, Anne, Bernard Rochet, Elizabeth Sovis and Dallyce Mielke. (1998). 'Characteristics of Nasalance in Speakers of Western Canadian English and French'. Journal of Speech-Language Pathology and Audiology, 22 (2):94103.

Seaver, Earl, Roger Dalston, Herbert Leeper and Larry Adams. (1991). 'A study of nasometric values for normal nasal resonance'. Journal of Speech Language and Hearing Research, 34:715-721.

Stevens, Kenneth, Raymond Nickerson, Arthur Boothroyd and Ann Rollins. (1976). 'Assessment of nasalization in the speech of deaf children'. Journal of Speech Language and Hearing Research, 19:393-416.

Tachimura, Takahsi, Chihiro Mori, So-ichiro Hirata and Takeshi Wada. (2000). 'Nasalance score variation in normal adult Japanese speakers of Mid-West Japanese dialect'. Cleft Palate-Craniofacial Journal, 37:463-467. 
Vallino-Napoli, Linda and Allen Montgomery. (1977). 'Examination of the standard deviation of mean nasalance scores in subjects with cleft palate: Implications for clinical use'. Cleft Palate-Craniofacial Journal, 34:512519.

Van de Weijer, Jeroen and Iman Hans Slis. (1991). 'Nasaliteitsmeting met de nasometer'. Logopedie Foniatrie, 63:97-101.

Van Doorn, Jan and Alison Purcel. (1998). 'Nasalance levels in the speech of normal Australian children'. Cleft Palate-Craniofacial Journal, 35:287-92.

Van Lierde, Kristiane, John Van Borsel, An Cardinael, Stephanie Reeckmans and Katrien Bonte. (2011). 'The impact of vocal intensity and pitch modulation on nasalance scores: A pilot study'. Folia Phoniatrica et Logopaedica, 63:21-26.

Van Lierde, Kristiane, John Van Borsel, Mieke Moerman and Paul van Cauwenberge. (2002). 'Nasalance, nasality, voice, and articulation after uvulopalatopharyngoplasty'. The Laryngoscope, 112:873-878.

Van Lierde, Kristiane, Frederik Wuyts, Marc De Bodt and Paul van Cauwenberge. (2003). 'Age-related patterns of nasal resonance in normal Flemish children and young adults'. Scandinavian Journal of Plastic and Reconstructive Surgery and Hand Surgery, 37:344-350.

Whitehill, Tara. (2001). 'Nasalance measures in Cantonese-speaking women'. Cleft Palate-Craniofacial Journal, 38:119-125. 


\section{Appendix 1. Phonetic transcription of the reading passage}

\section{bajtul batt}

jațưu ssaba:hu fala: bajtilbatt, fatshu wata?kulu thabb watafrabu hatta tawrtawi, faido ?adhat, tawadzdzahat lbattat lila ssa:hati lkabi:rah lita?kula wa taliab, wa tafkura rabbaha: wahibilhaja:ti warrizqi wa tusalli: lahu.

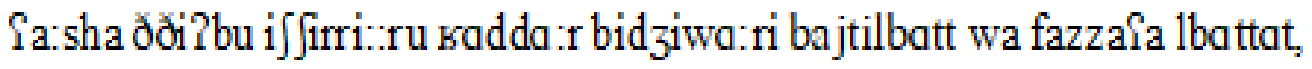
wa $7 a d a$ hajataha tha dila, fatalaqat kibartul lbattat wa $\chi$ abiratuaha:

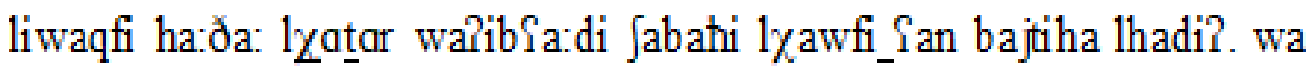
baida tu:li ldzida ali ttahadat ?ara ?u lbattat Sala qita li ðdi ibi bikulli ma tasti:i.

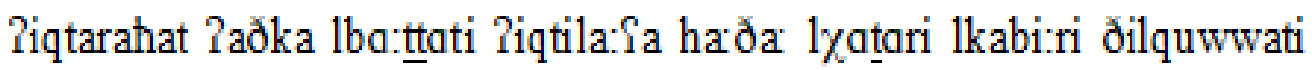
waldzabaru:ti lila liabad. wattafaqat kabiratu lbattati lala stidradzi

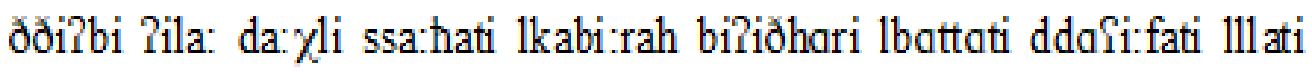

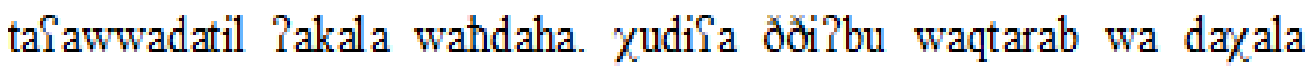
ssahata lkabi:rah, fatawwaqat lbattatu doirba min kulli ttildzah wa ro: hat tadribuhu bikulli qiwaha, fa dzuruha wa $\chi$ a:ra:t qiwah wa harab wa lam jaiud baida da:lik ?ila ssa:hati lkabi:rah. 